Alain Y. Li, Andreanne Segalla, Chao-Jun Li, and Audrey Moores. Mechanochemical MetalFree Transfer Hydrogenation of Carbonyls Using Polymethylhydrosiloxane as the Hydrogen Source. ACS Sustainable Chemistry \& Engineering 20175 (12), 11752-11760 DOI: 10.1021/acssuschemeng.7b03298

\title{
Mechanochemical metal-free transfer hydrogenation
}

\author{
of carbonyls using polymethylhydrosiloxane as \\ hydrogen source
}

Alain Y. Li, Andreanne Segalla, Chao-Jun Li*, and Audrey Moores*

\section{Corresponding Authors}

*Audrey Moores. E-mail: Audrey.moores@mcgill.ca.

*Chao-Jun Li. E-mail: cj.li@mcgill.ca.

Centre for Green Chemistry and Catalysis, Department of Chemistry, McGill University, 801

Sherbrooke St. West, Montreal, QC, H3A 0B8, Canada

Keywords: Mechanochemistry, Carbonyl reduction, PMHS, HMF, Polyketone, Transfer hydrogenation.

\begin{abstract}
We report herein a new methodology for the rapid and selective reduction of carbonyls in the solid phase. By exploiting mechanical energy and using a cheap and air-stable silane, polymethylhydrosiloxane (PMHS), we can reduce a variety of carbonyl compounds, with catalytic
\end{abstract}


Alain Y. Li, Andreanne Segalla, Chao-Jun Li, and Audrey Moores. Mechanochemical MetalFree Transfer Hydrogenation of Carbonyls Using Polymethylhydrosiloxane as the Hydrogen Source. ACS Sustainable Chemistry \& Engineering 20175 (12), 11752-11760 DOI: 10.1021/acssuschemeng.7b03298

amounts of fluorides. A scope of 19 substrates was explored to probe the generality of the method. In addition, an important biomass-based platform chemical, 5-hydroxymethylfurfural (5-HMF) and an insoluble polymer, polyketone, could be reduced with this methodology. A mechanistic study is also presented, suggesting the active role of volatile silane species. This method is particularly appealing to overcome substrate solubility issues and reduce solvent reliance in organic synthesis.

\section{Introduction}

The reduction of carbonyls to alcohols is a key reaction in the chemical industry, spanning from the production of commodity chemicals to pharmaceutical compounds. ${ }^{1}$ On the lab scale, this is often done using stoichiometric amounts of hydrides, such as $\mathrm{NaBH}_{4}$ or $\mathrm{LiAlH}_{4}{ }^{2}$ Catalytic methods relying on transition metals allowed to unravel the potential of molecular hydrogen gas for this reaction, via the development of highly active and chemo-, regio- and enantioselective systems, with high atom-economy. ${ }^{3}$ Alternatively, catalytic transfer hydrogenation reactions have been developed, whereby cheap and available hydrogen sources are selected, for instance alcohols, with the advantage of alleviating the need for high pressure. ${ }^{4}$ Alternative reducing agents such as sodium formate, ${ }^{5}$ Hantzch ester, ${ }^{6}$ various isopropoxides, ${ }^{7}$ or silanes ${ }^{8}$ have been successfully reported. They also pave the way for hydrogen borrowing strategies, as green cascade methodology to build molecular complexity in one-pot. ${ }^{9}$

Polymethylhydrosiloxane ( $\mathrm{Me}_{3} \mathrm{Si}-(\mathrm{OSiMeH})_{n} \mathrm{OSiMe}_{3}$, abbreviated as PMHS) was first reported by Nitzsche and Wick in 1957 for the reductive silylation of carbonyls with organotin compounds. As a waste of the silicon industry, PMHS is an inexpensive and abundant chemical with reducing 
Alain Y. Li, Andreanne Segalla, Chao-Jun Li, and Audrey Moores. Mechanochemical MetalFree Transfer Hydrogenation of Carbonyls Using Polymethylhydrosiloxane as the Hydrogen Source. ACS Sustainable Chemistry \& Engineering 20175 (12), 11752-11760 DOI: 10.1021/acssuschemeng.7b03298

abilities. ${ }^{10}$ Contrary to other silanes, it benefits as well from its non-toxicity, moisture stability, and ability for its $\mathrm{Si}-\mathrm{H}$ bonds to be easily activated under mild conditions.

Since then, it has been explored in solution phase with different activators such as titanium, ${ }^{11}$ copper, ${ }^{12}$ iron, ${ }^{13}$ zinc, ${ }^{14}$ TFA, ${ }^{15}$ fluorides, ${ }^{16}$ or bases. Typically, Kobayashi et al. used stoichiometric amounts of tert-butyl ammonium fluoride (TBAF) or $\mathrm{KF}$, at -70 or $0^{\circ} \mathrm{C}$, to perform both the hydrosilylation and the subsequent Si-O bond cleavage (Scheme 1A). ${ }^{17}$ Notably, this scheme based on silicon and fluoride chemistry is completely transition metal-free, and parts from the use of hazardous traditional hydrides. Further developments involved the use of potassium tertbutoxide and hydroxide to activate PMHS as shown by the Nikonov group. ${ }^{18}$ Their mechanistic studies show a base-induced rearrangement of the polymer into shorter volatile hypervalent silicon species, highly active for carbonyl reduction. PMHS is also a suitable reagent for the chiral reduction of carbonyls. ${ }^{19}$

Beyond carbonyl reduction, silane chemistry has recently been highlighted as a powerful reagent to develop metal-free and non-toxic organic pathways. Cantat et al. reported the conversion of $\mathrm{CO}_{2}$ to afford amine formylation products ${ }^{20}$ or formamidine derivatives, using PMHS. ${ }^{21}$ They also used Si-H bond as part of a frustrated Lewis Pair (FLP) scheme to reduce $\mathrm{CO}_{2}{ }^{22}$ The Beller group showed as well the convenient conversion of amides into amines with PHMS. $^{23}$ 
Alain Y. Li, Andreanne Segalla, Chao-Jun Li, and Audrey Moores. Mechanochemical MetalFree Transfer Hydrogenation of Carbonyls Using Polymethylhydrosiloxane as the Hydrogen Source. ACS Sustainable Chemistry \& Engineering 20175 (12), 11752-11760 DOI: 10.1021/acssuschemeng.7b03298

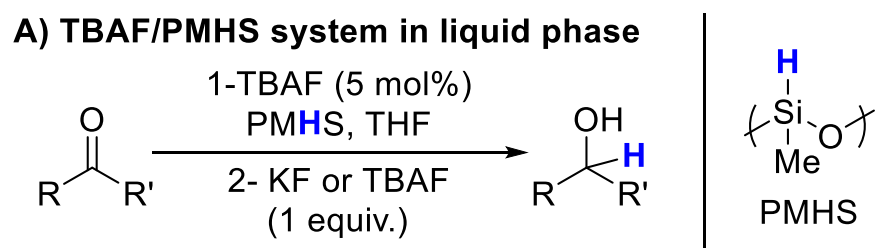

B) $\mathrm{NaBH}_{4}$ using mortar and pestle

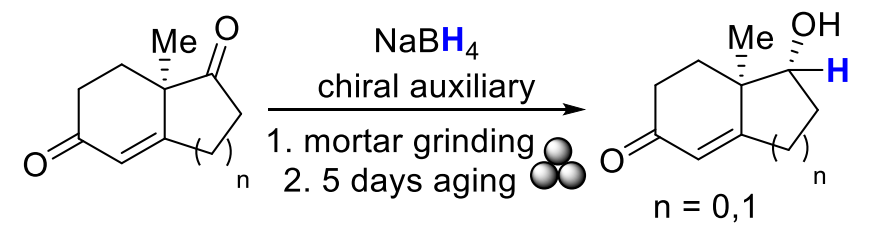

C) $\mathrm{NaBH}_{4}$ in ball mill

$$
\mathrm{n}=0,1
$$

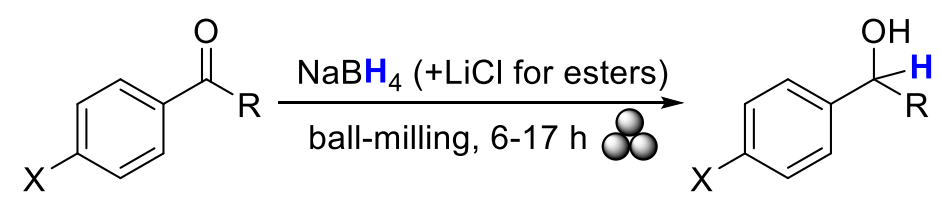

D) This work

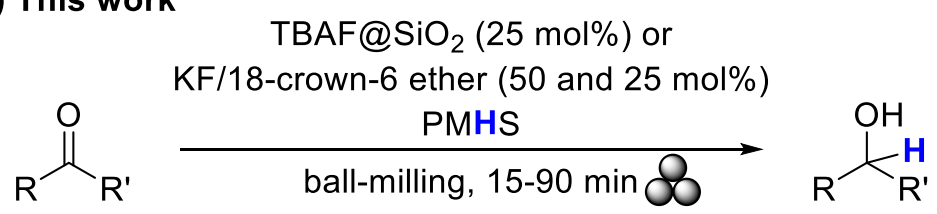

Scheme 1. Selected liquid phase and mechanochemical strategies for carbonyl reduction.

All these methods however call for the use of solvents, either to ensure good gas miscibility, since gas-liquid mixing is often rate-determining, ${ }^{24}$ or as the "hydrogen" provider itself. ${ }^{25}$ Yet, solvents contribute significantly to waste generation in the chemical enterprise. For instance, an estimation published by Glaxo-Smith-Kline revealed that solvents represented $85 \%$ of the total mass of chemicals used in pharmaceutical manufacture. ${ }^{26}$ Recently, mechanochemistry, a method enabling reactions in solid phase, with limited amounts or no solvents, and using mechanical energy emerged as an interesting alternative to liquid-phase methodologies. ${ }^{27}$ It also offers new solutions for addressing issues related to recalcitrant or insoluble substrates. ${ }^{28}$

Despite the rising popularity of ball-milling, it has been seldom investigated for carbonyl reduction methodology. Toda et al. reported the reduction of ketones using $\mathrm{NaBH}_{4}$ by mortar grinding and 
Alain Y. Li, Andreanne Segalla, Chao-Jun Li, and Audrey Moores. Mechanochemical MetalFree Transfer Hydrogenation of Carbonyls Using Polymethylhydrosiloxane as the Hydrogen Source. ACS Sustainable Chemistry \& Engineering 20175 (12), 11752-11760 DOI: 10.1021/acssuschemeng.7b03298

aging in a dry atmosphere for 5 days. ${ }^{29}$ They could synthesize a range of chiral hydroxyketones of synthetic interest with 100\% ee using (+)-taddol as a chiral auxiliary Scheme 1B). Mack and coauthors reported the use of $\mathrm{NaBH}_{4}$ in ball milling to reduce a wide range of aromatic carbonyls. ${ }^{30}$ By adding $\mathrm{LiCl}$, they could generate $\mathrm{LiBH}_{4}$ in situ and reduce esters, although after several hours of milling (Scheme 1C). This system was further studied by Naimi-Jamal et al., ${ }^{31}$ who analyzed the sodium tetraalkoxyborate intermediates as well as the selectivity of the reaction. Alternatively, Wang et al. performed the reductive amination of aromatic aldehydes, using Hantzch ester as a reductant and zinc chloride as a catalyst. ${ }^{32}$ These examples are, to the best of our knowledge, the only examples of solid-state reduction of carbonyls and imines. ${ }^{33}$ Although $\mathrm{NaBH}_{4}$ and the Hantzch ester are highly popular, they suffer from safety issues for the former, ${ }^{34}$ and toxicity issues for the latter, including the generation of pyridine derivative as byproducts. ${ }^{35}$

In our continued efforts to develop greener chemical reductions, we herein present the reduction of carbonyls using ball milling, with catalytic amounts of solid fluorides to activate polymethylhydrosiloxane, as an industrial waste, stable and non-toxic hydrogen source. The method afforded moderate to excellent yields on a range of substrates, in short reaction times. Importantly, it opened avenues to address separation issues in the context of 5hydroxymethylfurfural (5-HMF) hydrogenation and solubility issues for a polyketone reduction.

\section{Results and discussion}

In this study, we used a mixer mill operating 2 Teflon jars at $29.5 \mathrm{~Hz}$, each equipped with 1 zirconium oxide ball. To develop the methodology, we first focused on 4-formylbenzonitrile as a model substrate. Indeed, as a solid electron-poor aromatic aldehyde, it is expected to be reactive 
Alain Y. Li, Andreanne Segalla, Chao-Jun Li, and Audrey Moores. Mechanochemical MetalFree Transfer Hydrogenation of Carbonyls Using Polymethylhydrosiloxane as the Hydrogen Source. ACS Sustainable Chemistry \& Engineering 20175 (12), 11752-11760 DOI: 10.1021/acssuschemeng.7b03298

under reduction conditions. Several fluoride salts, including KF, LiF and TBAF@SiO examined.We found that TBAF@ $\mathrm{SiO}_{2}$, a silica-supported fluoride source, was the most successful to activate PMHS with the model substrate. It is a less hygroscopic fluoride source than its liquid counterparts, which we reasoned could prevent any potential water-quenching of the activated silane. As reaction conditions were optimized, we realized that 0.25 equivalent of TBAF@ $\mathrm{SiO}_{2}$ was sufficient in activating PHMS, which is an improvement compared to the Kobayashi's solution methodology relying on stoichiometric amounts of fluoride. ${ }^{17}$ We had initially conducted the optimization phase using stainless steel jars and a stainless ball for milling. Eventually, we moved to the current apparatus due to their lower price and similar performance. Furthermore, we had concerns that stainless steel could react with the mixture, as had been reported previously by our group. ${ }^{36}$ We used $\mathrm{ZrO}$ balls as they were more durable on the long run than Teflon balls. After optimizing quantity of reagents and milling time, the corresponding alcohol, 4(hydroxymethyl)benzonitrile, was obtained in $82 \%$ yield within 15 minutes of milling, using 25\% TBAF@ $\mathrm{SiO}_{2}$ and 1.7 equivalents of PMHS (Table 1, entry 1).

In an effort to improve the reaction rates, addition of stoichiometric amounts of solvent was tested (typically $0.5 \mu \mathrm{L}$ per mg of substrate). This method, also known as liquid-assisted grinding (LAG), 37 has been successful, for instance in the synthesis of metal organic frameworks, ${ }^{38}$ cocrystallizations, ${ }^{39}$ or selective fluorination. ${ }^{40}$ Adding ethyl acetate increased the yield to $94 \%$ (Table 1, entry 2). Addition of toluene afforded a moderate yield improvement to $87 \%$, while with THF and notably water, the reaction performance was unchanged (Table 1, entries 3 to 5). As we will discuss below, the effect of the choice of LAG solvent greatly varied depending on the substrate. Control experiments were conducted to ascertain the role of each component in the 
Alain Y. Li, Andreanne Segalla, Chao-Jun Li, and Audrey Moores. Mechanochemical MetalFree Transfer Hydrogenation of Carbonyls Using Polymethylhydrosiloxane as the Hydrogen Source. ACS Sustainable Chemistry \& Engineering 20175 (12), 11752-11760 DOI: 10.1021/acssuschemeng.7b03298

system. Replacing TBAF@ $\mathrm{SiO}_{2}$ with $\mathrm{KF}$ or LiF (Table 1, entries 6 and 7) or removing either the fluoride source or the PMHS (Table 1, entries 8 and 9) totally disabled the reaction.

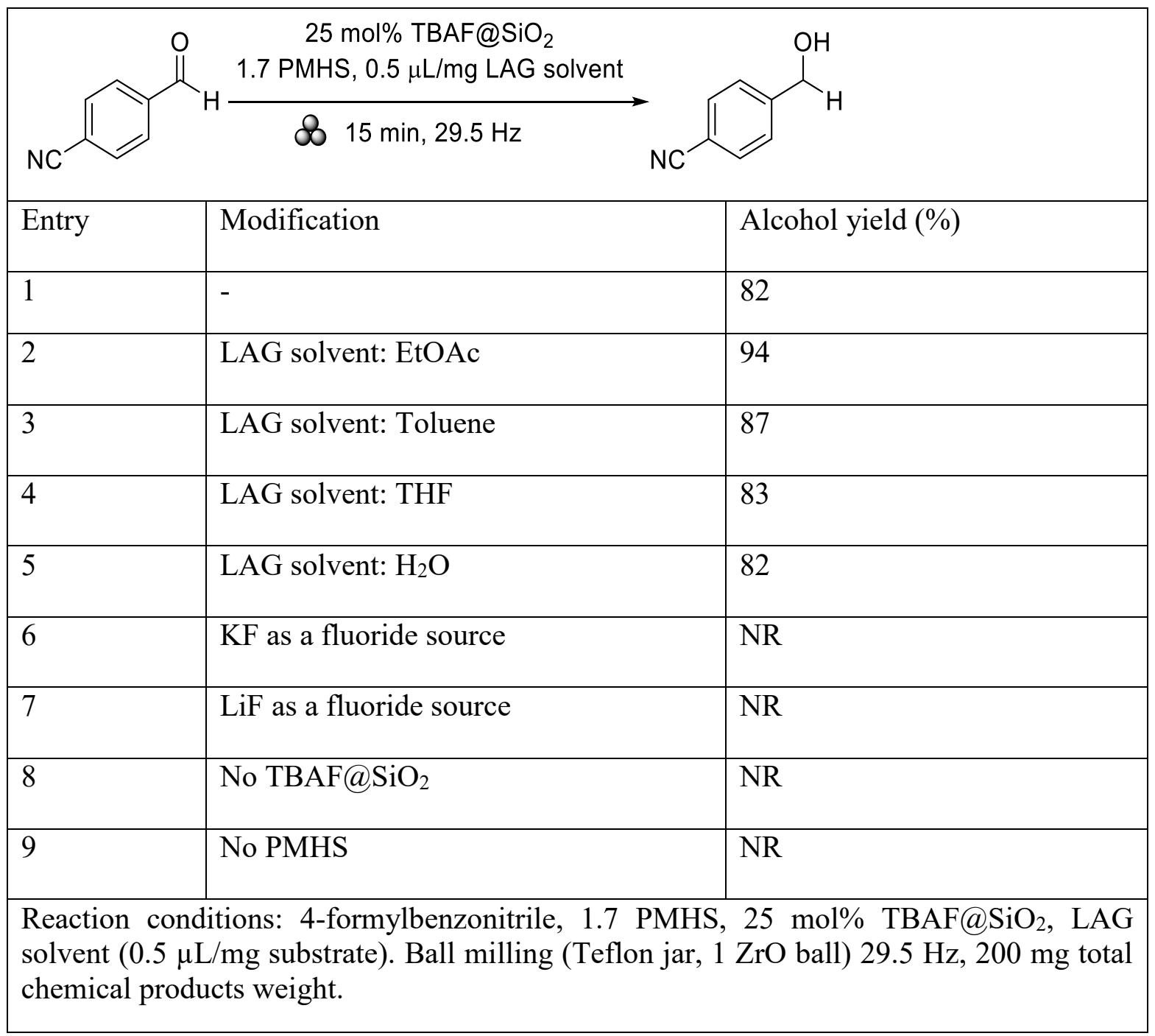

Table 1. Control experiments.

Next were investigated benzaldehyde derivatives. Milling time, fluoride source, and choice of LAG solvent were optimized for each substrate. Electron-poor benzaldehydes such as 4formylbenzonitrile, 4-nitrobenzaldehyde, 4-(trifluoromethyl)benzaldehyde and 3bromobenzaldehyde (Table 2, entries 1 to 4 ) gave high yields between $78 \%$ to quantitative. Ethyl acetate was the best LAG solvent there, except for 4-nitrobenzaldehyde, which worked better in 
Alain Y. Li, Andreanne Segalla, Chao-Jun Li, and Audrey Moores. Mechanochemical MetalFree Transfer Hydrogenation of Carbonyls Using Polymethylhydrosiloxane as the Hydrogen Source. ACS Sustainable Chemistry \& Engineering 20175 (12), 11752-11760 DOI: 10.1021/acssuschemeng.7b03298

absence of such an additive. Notably 4-(trifluoromethyl)benzaldehyde worked well under milling conditions despite being a liquid at room temperature. Chloride-substituted benzaldehydes proved to give different optimal results depending on the position of the substituent, ranging from $56 \%$ for 2-chlorobenzaldehyde to $73 \%$ for 4-chlorobenzaldehyde and $96 \%$ for 3-chlorobenzaldehyde, with the optimal LAG solvent being none, toluene and ethyl acetate respectively (Table 2, entries 5 to 7). 4-Ethynylbenzaldehyde and 9-anthracenecarboxaldehyde, as electron-rich substrates, were successfully reduced at yields of $84 \%$ and $72 \%$, respectively, with no LAG solvent and ethyl acetate respectively (Table 2, entries 8 and 9). 1,2-conjugated unsaturated carbonyls, such as citral, were successfully reduced in moderate yields of $65 \%$ with toluene as LAG solvent, despite its lower reactivity due to the absence of a benzylic position (Table 2 , entry 10 ). No trace of the $\mathrm{C}=\mathrm{C}$ reduction product was detected, showing excellent selectivity. For 4-nitrocinnamaldehyde, initial results gave $28 \%$ yield after 15 minutes of milling (Table 2, entry 11 ). Extending reaction time did not significantly alter the reaction progress. We reasoned that catalysts was likely degrading under the milling conditions. Inspired by the approach of the Friscic group, ${ }^{41}$ we fractioned the addition of PMHS into three portions of 1 equivalent each, followed by 10 minutes of milling and successfully increased the yield from 28\% to 63\% (Table 2, entry 12, with 50 mol\% TBAF@ $\mathrm{SiO}_{2}$ added once at the beginning of the reaction). Protic aldehydes and imines showed no reactivity to the reaction (Table 2, entries 13 to 15). Most examples in the literature seem to indicate that imine hydrosilylation does not seem to proceed under fluoride activation unless a Lewis acid or a transition metal catalyst is added. We attempted to use $\mathrm{Zn}(\mathrm{OTf})_{2}$ as a Lewis acid to activate the imine, unfortunately to no avail (Table 2, entry 14). With our system, the reaction proceeded very fast, with 15 minutes being the optimal reaction time. Prolonging the reaction for longer than 15 minutes usually does not improve the yield, pointing towards the fast degradation of the active 
Alain Y. Li, Andreanne Segalla, Chao-Jun Li, and Audrey Moores. Mechanochemical MetalFree Transfer Hydrogenation of Carbonyls Using Polymethylhydrosiloxane as the Hydrogen Source. ACS Sustainable Chemistry \& Engineering 20175 (12), 11752-11760 DOI: 10.1021/acssuschemeng.7b03298

species. In comparison, the reaction times in the carbonyl reduction with $\mathrm{NaBH}_{4}$ was longer, with milling between 6 and 17 hours, ${ }^{30}$ while reduction by the Hantzch ester proceeded within 90 minutes of milling. ${ }^{32}$

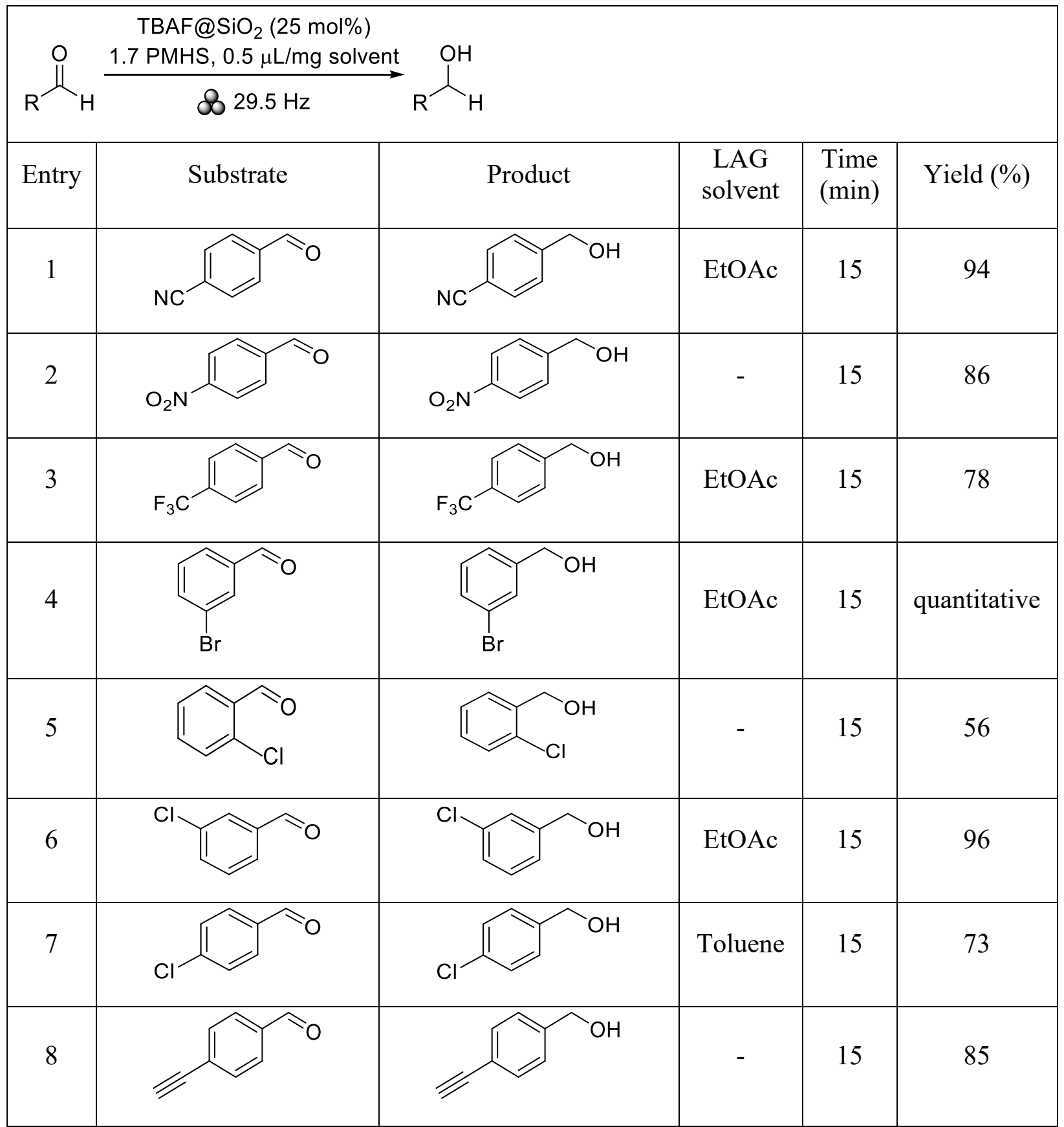


Alain Y. Li, Andreanne Segalla, Chao-Jun Li, and Audrey Moores. Mechanochemical MetalFree Transfer Hydrogenation of Carbonyls Using Polymethylhydrosiloxane as the Hydrogen Source. ACS Sustainable Chemistry \& Engineering 20175 (12), 11752-11760 DOI: 10.1021/acssuschemeng.7b03298

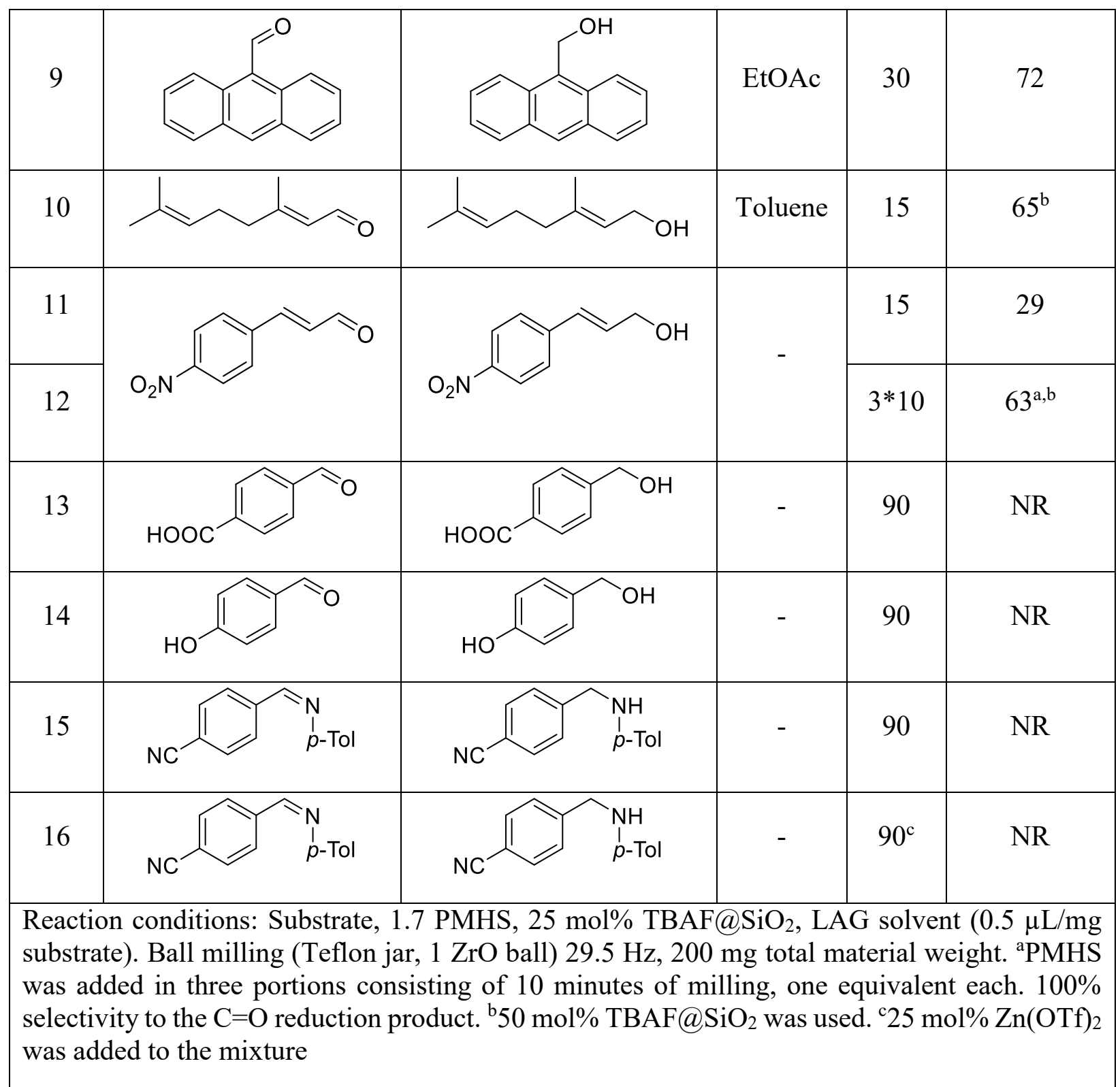

Table 2. Scope of aldehydes.

Ketones were then investigated. Electron-poor acetophenones such as 4'-nitroacetophenone, 4'bromoacetophenone, and 4'-iodoacetophenone (Table 3, entries 1 to 3) gave high yields, ${ }^{42}$ following a similar trend to previously reported. With 4'-nitroacetophenone, using 25\% TBAF@ $\mathrm{SiO}_{2}$ gave a 71\% yield after 90 minutes of milling. In an effort to improve this reaction, we screened again fluorides. While KF gave no reaction, the addition of 25\% 18 -crown- 6 ether in conjunction with $50 \% \mathrm{KF}$ increased the yield to $81 \%$ after only 15 minutes of milling (Table 3 , 
Alain Y. Li, Andreanne Segalla, Chao-Jun Li, and Audrey Moores. Mechanochemical MetalFree Transfer Hydrogenation of Carbonyls Using Polymethylhydrosiloxane as the Hydrogen Source. ACS Sustainable Chemistry \& Engineering 20175 (12), 11752-11760 DOI: 10.1021/acssuschemeng.7b03298

entry 1). The crown ether is known to coordinate with the $\mathrm{K}^{+}$cation to enhance the reactivity of the F- anion, as previously applied by Goldberg et $a l$. in solution phase. ${ }^{43}$ Similarly to aldehydes, electron-rich or sterically hindered ketones such as 2',6'-dimethoxyacetophenone, 4'methoxyacetophenone, 4-methylbenzophenone and 4-bromobenzophenone proved to be more challenging, giving no reaction to low yields (Table 3, entries 4 to 7). In the case of 4methylbenzophenone, increasing the milling time from 30 minutes to 90 minutes decreased the yield from $59 \%$ to $44 \%$ (Table 3 , entry 6), hinting at a possible degradation of the product. 2bromo-4'-nitroacetophenone was reduced in moderate yield (46\%) with 25\% TBAF@ $\mathrm{SiO}_{2}$, while preserving the reactive bromine functionality (Table 3, entry 8). Our system proved completely inactive on aliphatic ketones such as cyclopentanone and camphor (Table 3, entries 9 to 10).

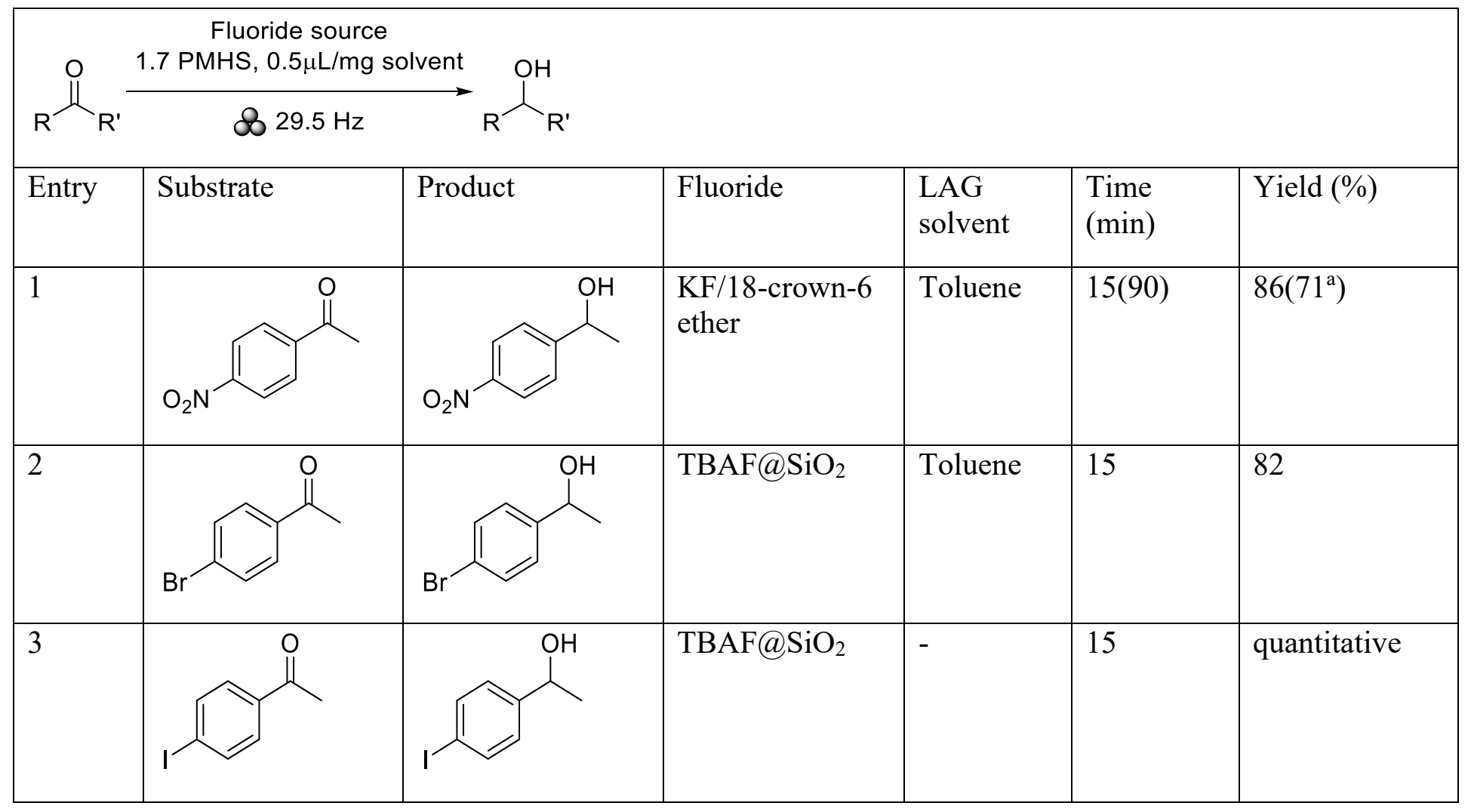


Alain Y. Li, Andreanne Segalla, Chao-Jun Li, and Audrey Moores. Mechanochemical MetalFree Transfer Hydrogenation of Carbonyls Using Polymethylhydrosiloxane as the Hydrogen Source. ACS Sustainable Chemistry \& Engineering 20175 (12), 11752-11760 DOI:

10.1021/acssuschemeng.7b03298

\begin{tabular}{|c|c|c|c|c|c|c|}
\hline 4 & OMe O & $\mathrm{OMe} \mathrm{OH}$ & TBAF@SiO & - & 90 & NR \\
\hline 5 & & & TBAF@SiO ${ }_{2}$ & EtOAc & 15 & 47 \\
\hline 6 & & & TBAF@SiO ${ }_{2}$ & - & $30(90)$ & $59(44)^{b}$ \\
\hline 7 & & & $\begin{array}{l}\text { KF/18-crown-6 } \\
\text { ether }\end{array}$ & Toluene & 15 & 40 \\
\hline 8 & & & TBAF@SiO ${ }_{2}$ & EtOAc & 15 & 46 \\
\hline 9 & & & TBAF@SiO $\mathrm{SiO}_{2}$ & - & 90 & NR \\
\hline 10 & & & TBAF@SiO ${ }_{2}$ & - & 90 & NR \\
\hline & & & $\begin{array}{l}\text { TBAF@SiO } \\
\text { flon jar, } 1 \mathrm{ZrO} \\
\text { ninutes of mill }\end{array}$ & $\begin{array}{l}0 \text { molo } \\
\text { l1) } 29.5 \\
\text { bYield }\end{array}$ & $\begin{array}{l}25 \mathrm{~mol} \\
00 \mathrm{mg} \\
\text { arenthes }\end{array}$ & $\begin{array}{l}\text {-crown-6 ether, } \\
\text { naterial weight. } \\
\text { BAF@ } \mathrm{SiO}_{2} 25\end{array}$ \\
\hline
\end{tabular}

Table 3. Scope of ketones. 
Alain Y. Li, Andreanne Segalla, Chao-Jun Li, and Audrey Moores. Mechanochemical MetalFree Transfer Hydrogenation of Carbonyls Using Polymethylhydrosiloxane as the Hydrogen Source. ACS Sustainable Chemistry \& Engineering 20175 (12), 11752-11760 DOI: 10.1021/acssuschemeng.7b03298

To prove the feasibility of the process on the gram scale, the reaction was tested in a planetary mill (Scheme 2). After 30 mins of milling at 500 rotations per minute, an isolated yield of $78 \%$ was afforded.

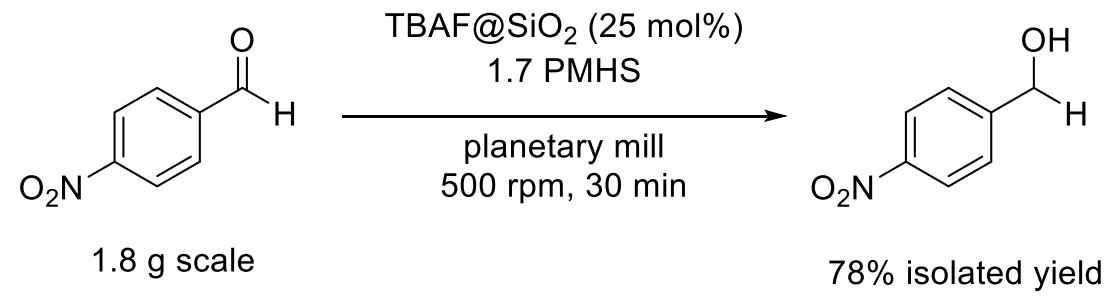

Scheme 2. Gram scale reduction of 4-nitrobenzaldehyde.

In an effort to showcase the intrinsic advantages of our system, we investigated specific substrates, where the liquid phase reaction shows limitations. 5-hydroxymethylfurfural (HMF) is a platform biomass-based chemical that can be produced from the triple dehydration of hexoses. ${ }^{44}$ It can be used as a starting material to access a wide range of furan-type compounds. For instance, the aldehyde function can be reduced to obtain 2,5-dihydroxymethylfurfural (DHMF). However, both HMF and DHMF are difficult to extract from water due to their low partition coefficient. ${ }^{45}$ Liu et al. reported 2-butanol/THF 1:4 ratio as an efficient mixture for HMF extraction. ${ }^{46}$ Continuous extraction in biphasic systems such as water/methyl isobutyl ketone (MIBK) mixtures was also reported. ${ }^{47}$ All these methods are intricate and require complicated solvent mixtures. Under our standard conditions, with 25 mol\% TBAF@SiO $2,1.7$ equivalents of PMHS, and milling for $15 \mathrm{~min}$ at $29.5 \mathrm{~Hz}$, only $36 \%$ of the product was obtained (Table 4, entry 1). Adding toluene as a LAG solvent only afforded a minor yield increase to $41 \%$ (Table 4 , entry 2 ) and increasing the milling time did not change the yield (Table 4, entry 3). Varying milling times between 15 and 90 
Alain Y. Li, Andreanne Segalla, Chao-Jun Li, and Audrey Moores. Mechanochemical MetalFree Transfer Hydrogenation of Carbonyls Using Polymethylhydrosiloxane as the Hydrogen Source. ACS Sustainable Chemistry \& Engineering 20175 (12), 11752-11760 DOI: 10.1021/acssuschemeng.7b03298

minutes with or without a LAG solvent afforded at the best a 50\% yield (Table S3). Again, by fractioning the addition of PMHS to the reaction mixture into three equal portions of one equivalent each with 10 minutes of milling upon each addition, the yield could be increased to $69 \%$ (Table 4, entry 4). Interestingly, after reaction, both the product and the starting material were easily extracted with ethyl acetate, and a simple filtration. As no water was introduced during either the reaction or the work-up, this procedure solves very simply the challenge of separating HMF and its products from reaction mixtures. To the best of our knowledge, this constitutes the first example of HMF reduction to DHMF in ball-milling. ${ }^{48} \mathrm{~A}$ more thorough comparison to other reports in liquid phase is provided in supporting information, as well as a further investigation on carbon mass balance (Table S4).

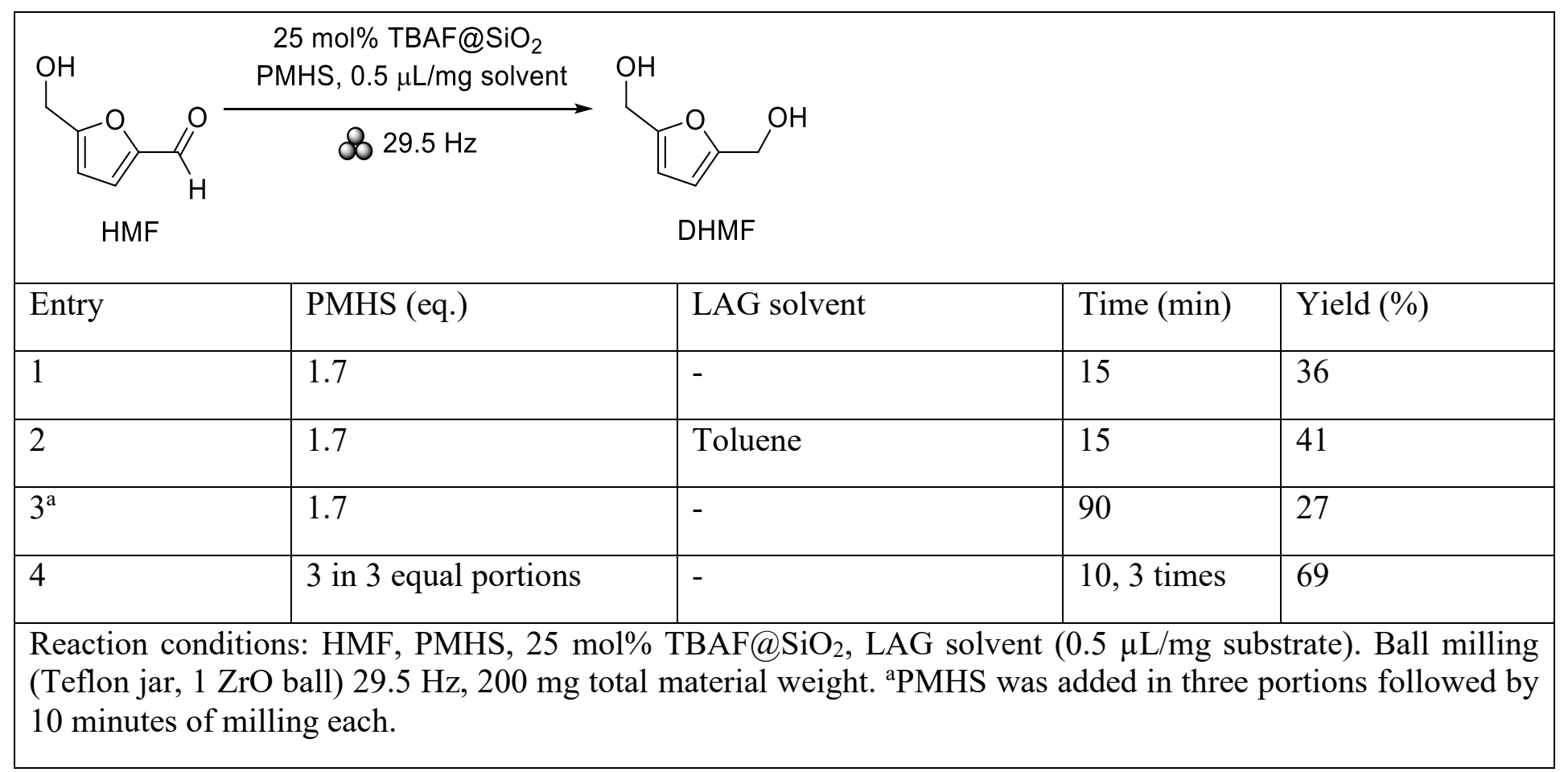

Table 4. HMF reduction.

Finally, we explored the opposite side of the solubility issue. Polyketones are a class of thermoplastic polymers developed by Shell Chemicals (under the name of Carilon) and produced 
Alain Y. Li, Andreanne Segalla, Chao-Jun Li, and Audrey Moores. Mechanochemical MetalFree Transfer Hydrogenation of Carbonyls Using Polymethylhydrosiloxane as the Hydrogen Source. ACS Sustainable Chemistry \& Engineering 20175 (12), 11752-11760 DOI: 10.1021/acssuschemeng.7b03298

now by Hyosung. Among other interesting properties, they possess a significantly higher melting point than their polyethylene counterparts, and a low solubility in most solvents. They are produced from CO/olefin copolymerization. ${ }^{49}$ Polyketones have a very poor solubility in most solvents. The hydrogenation of their carbonyl functionality has been investigated as a means to improve their ability to dissolve in protic media. In this scheme, even partial reduction can be beneficial. The reduction of polyketones has been reported by Milani and co-workers with the transfer hydrogenation of atactic $\mathrm{CO} / 4-\mathrm{Me}$-styrene polyketones in liquid phase. ${ }^{50}$ Using a 2propanol/dioxane 5:3 mixture and $\left[\operatorname{Ir}(\operatorname{cod})\left(\mathrm{Me}_{2}\right.\right.$ bipy $\left.) \mathrm{Cl}\right]$ as a catalyst, they obtained a $70 \%$ conversion of the polymer into the corresponding polyalcohol. To the best of our knowledge, this is the sole example of polyketone reduction in the literature. We were interested in exploring this reaction by mechanochemistry, as this methodology has been shown in recent examples to afford sustainable solutions for polymer functionalization and deconstruction challenges. ${ }^{28,51}$ We also saw an opportunity to perform this reaction without relying on any metal. For this reaction, we synthesized polyketone, using Pd catalyzed styrene and carbon monoxide copolymerization with a procedure adapted from Guo et $a .^{52}$ In this fashion, we obtained a polyketone sample of featuring a number average molecular weight of $2200 \mathrm{~g} / \mathrm{mol}$ and weight average molecular weight of $2400 \mathrm{~g} / \mathrm{mol}$, as determined by matrix-assisted laser desorption/ionization - time of flight (MALDI-TOF). The complete insolubility of polyketone in common solvents, prevented any further characterization by gel permeation chromatography (GPC). We then loaded this sample in a stainless steel jar with 2 balls to increase the impact energy, compared to the small molecule substrates. The conversion of $\mathrm{C}=\mathrm{O}$ into $\mathrm{C}-\mathrm{O}$ was monitored by $\mathrm{X}$-ray photoelectron spectroscopy (XPS). After 90 mins of milling and 2 days of aging $54 \%$ of the $\mathrm{C}=\mathrm{O}$ bonds were converted to $\mathrm{C}$ O bonds (Scheme 3). 
Alain Y. Li, Andreanne Segalla, Chao-Jun Li, and Audrey Moores. Mechanochemical MetalFree Transfer Hydrogenation of Carbonyls Using Polymethylhydrosiloxane as the Hydrogen Source. ACS Sustainable Chemistry \& Engineering 20175 (12), 11752-11760 DOI:

10.1021/acssuschemeng.7b03298

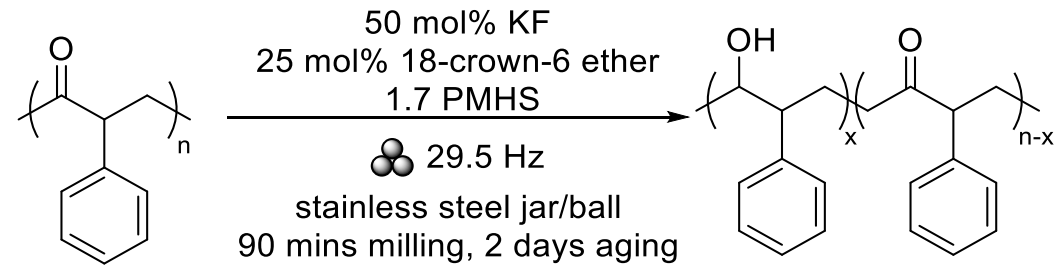

Scheme 3. Polyketone reduction

\section{Mechanism}

The reaction of reduction of carbonyls in the solution phase by PMHS has been studied by other researchers. Lawrence originally proposed a 'zipper' mechanism where the fluoride migrates from one monomer to another, activating several Si-H bonds in the process (Scheme 4). ${ }^{10}$ 
Alain Y. Li, Andreanne Segalla, Chao-Jun Li, and Audrey Moores. Mechanochemical MetalFree Transfer Hydrogenation of Carbonyls Using Polymethylhydrosiloxane as the Hydrogen Source. ACS Sustainable Chemistry \& Engineering 20175 (12), 11752-11760 DOI: 10.1021/acssuschemeng.7b03298

a) Lawrence's 'zipper' mechanism

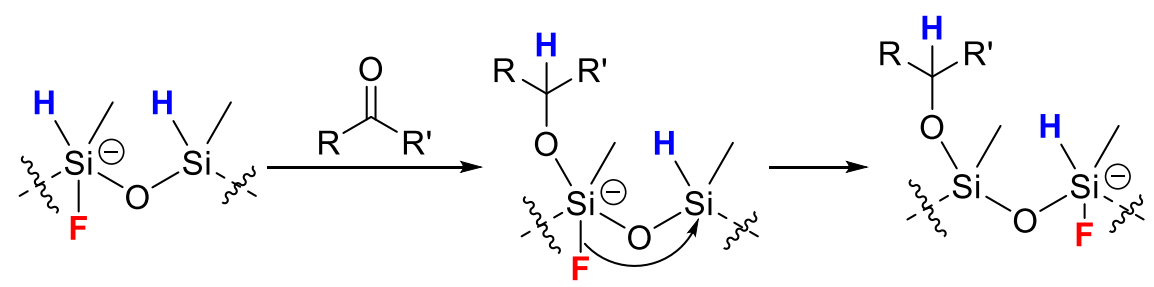

b) Nikonov's re-arrangement mechanism
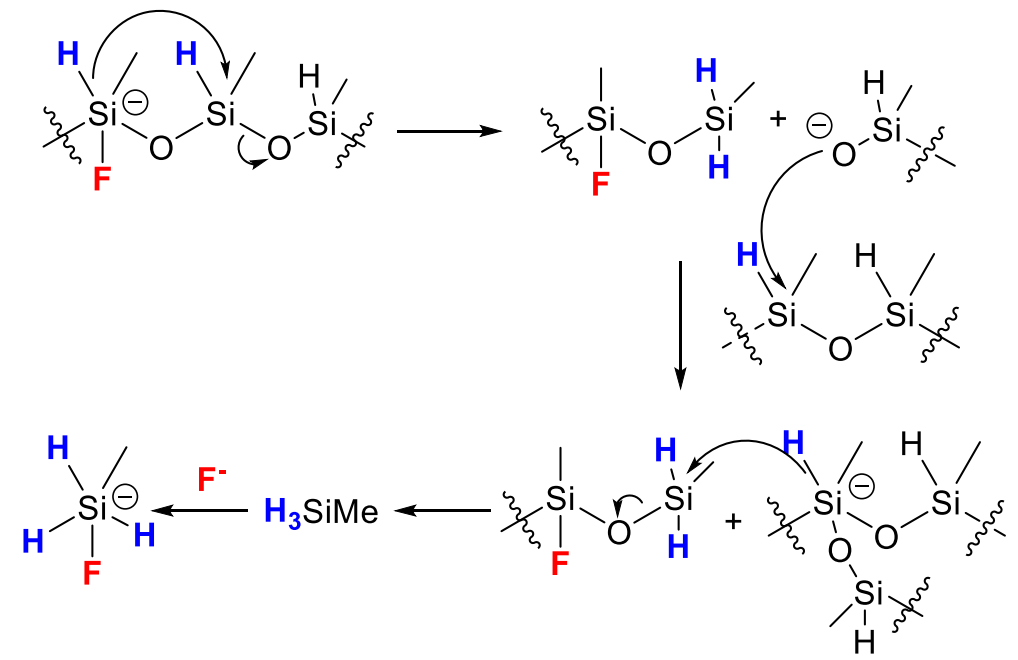

Scheme 4. Proposed mechanisms for the activation of PMHS with fluoride. For clarity, fluoride and active hydrides are highlighted in red and blue, respectively.

Nikonov and coworker revised the mechanism considering that the hydride may migrate along the PMHS chain and between ones, before the insertion of the carbonyl occurs. ${ }^{18}$ This leads to the rearrangement of the PMHS chain into oligomers and eventually monomeric, volatile $\mathrm{H}_{3} \mathrm{SiMe}$ (Error! Reference source not found.Scheme 4). $\mathrm{H}_{3} \mathrm{SiMe}$ can further react with fluoride to form $\left[\mathrm{H}_{3} \mathrm{SiFMe}\right]^{-}$, an hypercoordinate species. Nikonov was able to rationalize their observation that reactivity would drop in an open vessel in solution. In our case, such a mechanism can explain that we would observe gas pressure build-up in the jars when they were opened after the milling. 
Alain Y. Li, Andreanne Segalla, Chao-Jun Li, and Audrey Moores. Mechanochemical MetalFree Transfer Hydrogenation of Carbonyls Using Polymethylhydrosiloxane as the Hydrogen Source. ACS Sustainable Chemistry \& Engineering 20175 (12), 11752-11760 DOI: 10.1021/acssuschemeng.7b03298

In order to verify if the mechanochemical reduction reaction relied on the generation of reaction silicon volatiles, we performed a test experiment. Replicating the optimal conditions for the reduction of 4-formylnitrile (Table 2, entry 2), we first milled the PMHS and the TBAF@ $\mathrm{SiO}_{2}$ for 15 minutes alone, carefully opened the jar under the fumehood, and then added the aldehyde to be milled again for 15 minutes(Scheme 5). Only traces amount of product was formed, hinting at the active species are gaseous and easily escape the reaction vessel upon its opening.

\section{Two step test}

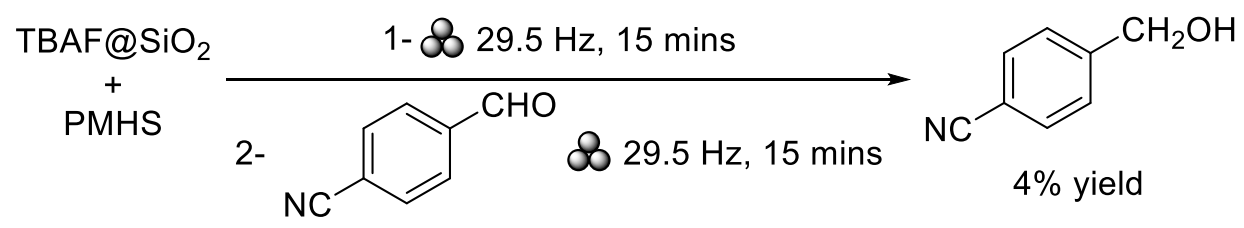

\section{Canula experiment}

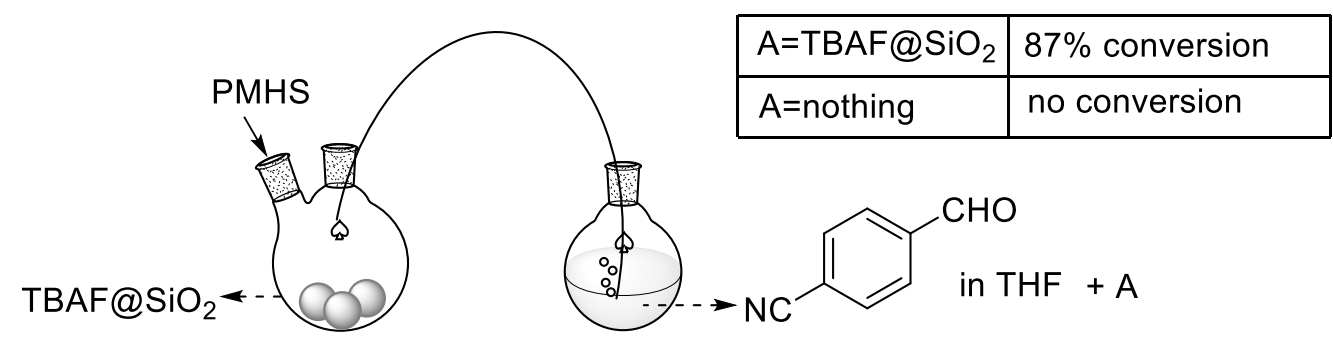

Scheme 5 Two-steps milling and canula experiments.

To further explore the possibility of a volatile active species, another experiment was designed. A $250 \mathrm{~mL}$ round-bottom flask containing TBAF@ $\mathrm{SiO}_{2}$ was sealed with $3 \mathrm{ZrO}$ balls to replicate ball milling conditions under stirring. It was connected to another sealed flask through a cannula immersed into a solution of 4-formylnitrile in THF (Scheme 5, Figure S2). Upon injecting PMHS in the first flask, we observed bubbling in the solution of the second flask, and interpreted this as formation of $\mathrm{H}_{3} \mathrm{SiMe}$. The set-up was left for $2 \mathrm{~h}$ under vigorous stirring for both flasks, resulting in no conversion of the aldehyde. In a second experiment, TBAF@ $\mathrm{SiO}_{2}$ was added also to the 
Alain Y. Li, Andreanne Segalla, Chao-Jun Li, and Audrey Moores. Mechanochemical MetalFree Transfer Hydrogenation of Carbonyls Using Polymethylhydrosiloxane as the Hydrogen Source. ACS Sustainable Chemistry \& Engineering 20175 (12), 11752-11760 DOI: 10.1021/acssuschemeng.7b03298

second flask. This time, after 2 hours, $87 \%$ of the alcohol product was measured. This result is consistent with the reaction of gaseous $\mathrm{H}_{3} \mathrm{SiMe}$ formed in flask 1, with the fluoride source in flask 2 to afford $\left[\mathrm{H}_{3} \mathrm{SiFMe}^{-}\right.$in situ, and this the alcohol, as Nikonov reported.

Finally, the role of water in the mechanism is worth mentioning. To our surprise, its presence totally shut down the reduction of 4-nitrobenzaldehyde or 4'-nitroacetophenone while it did not affect 4-formylbenzonitrile (Table 1, entry 5). we expect nitro-substituted compounds to favor the formation of acetals by hydrogen-bonding stabilization. ${ }^{53}$ A more detailed study on the influence of water on 4-formylbenzonitrile and 4-nitrobenzaldehyde reduction is provided in the supporting information.

In conclusion, we have developed a ball-milling approach for the selective reduction of a wide range of carbonyl compounds in the absence of any metal catalyst and using an inexpensive and easy-to-handle silane, PMHS. Ball-milling not only enabled a higher reaction rate than solutionbased reactions, with typical reaction times of 15 minutes, but it also allowed insoluble substrates to be reduced. We also confirmed that the reaction mechanism proceeded through the in situ formation of volatile silicon species, consistent with past accounts. Future studies will focus on removing solvents from the work-up as well, with solvent-free extraction methods such as supercritical carbon dioxide $\left(\mathrm{sCO}_{2}\right) .{ }^{54-55}$ With this system, we hope to expand the carbonyl reduction toolbox in mechanochemistry.

\section{Experimental}

All chemicals and solvents were purchased from commercial sources and used without purification unless noted. TBAF@ $\mathrm{SiO}_{2}(1.5 \mathrm{mmol} / \mathrm{g})$ was purchased from Sigma and was freezedried before use and stored in a desiccator. Alternatively, it can be made from TBAF in THF 
Alain Y. Li, Andreanne Segalla, Chao-Jun Li, and Audrey Moores. Mechanochemical MetalFree Transfer Hydrogenation of Carbonyls Using Polymethylhydrosiloxane as the Hydrogen Source. ACS Sustainable Chemistry \& Engineering 20175 (12), 11752-11760 DOI: 10.1021/acssuschemeng.7b03298

solution. The procedure is given in the supporting information. The molecular weight of PMHS was taken to be $65 \mathrm{~g} / \mathrm{mol}$ for calculations of stoichiometry. A Retsch MixerMill MM 400 was used to perform milling experiments. NMR spectra were recorded on a Bruker AV500 spectrometer operating at $500 \mathrm{MHz}$ for ${ }^{1} \mathrm{H}$ acquisitions and on a Varian VNMRS operating at $400 \mathrm{MHz}$ for the solid state ${ }^{13} \mathrm{C}$ acquisition. Chemical shifts are reported in ppm with a solvent resonance as an internal standard ( ${ }^{1} \mathrm{H}$ NMR; chloroform as internal standards, indicating $\left.7.26 \mathrm{ppm}\right)$. Mesitylene was used as an internal NMR standard. Yields were an average of a minimum of two different experiments. XPS was performed on a VG ESCALAB 3 MKII spectrometer (VG, Thermo Electron Corporation, UK) equipped with an $\mathrm{Mg} \mathrm{K \alpha}$ source. Polyketone copolymerization with carbon monoxide were carried out in a Parr Instruments 5000 Series Multiple Reactor System. MALDI-TOF measurement was taken on a MALDI Autoflex III- TOF-(BRUKER).

Typical procedure.

In a typical reaction, one zirconium oxide ball $(10 \mathrm{~mm}, 3.24 \mathrm{~g}$ weight $)$ was added in a $10 \mathrm{~mL}$ Teflon milling jar. It was then filled with a total of $200 \mathrm{mg}$ of solid reagent material on one side, and liquids on the other. The jar was carefully closed, wrapped with parafilm and loaded onto the Retsch MM-400 mixer mill. The reactions were conducted over 15 minutes, milling at a frequency of $29.5 \mathrm{~Hz}$. At the end of the reaction, the jar was opened under a fumehood, $5 \mathrm{~mL}$ of ethyl acetate were added to the jar, and was manually shaken with the balls for 20 seconds to scrape off the solid content. This operation was done three times to ensure a full product recovery. The three fractions were combined, sonicated for 10 seconds, and then concentrated in vacuo. To remove the PMHS byproducts and the activator, the mixture can be recrystallized or dissolved in an EtOAc/hexanes mixture and filtered through a silica plug. The imines were prepared by milling the corresponding aldehydes and amines in presence of $\mathrm{Na}_{2} \mathrm{SO}_{4}$. 
Alain Y. Li, Andreanne Segalla, Chao-Jun Li, and Audrey Moores. Mechanochemical MetalFree Transfer Hydrogenation of Carbonyls Using Polymethylhydrosiloxane as the Hydrogen Source. ACS Sustainable Chemistry \& Engineering 20175 (12), 11752-11760 DOI: 10.1021/acssuschemeng.7b03298

\section{ASSOCIATED CONTENT}

Details on the closed-flask experiments, planetary mill experiment, influence of water on the reduction of 4-nitrobenzaldehyde and 4-formylbenzonitrile, optimization details for the reduction of 5-HMF and the rest of the scope, comparison of 5-HMF reduction to other examples in the literature, discussion on the polyketone synthesis and characterization, and NMR of the model reaction product, comparison with the product made by $\mathrm{NaBH}_{4}$ reduction.

\section{AUTHOR INFORMATION}

\section{Corresponding Author}

*Audrey Moores. E-mail: Audrey.moores@mcgill.ca.

*Chao-Jun Li. E-mail: Cj.li@mcgill.ca.

Centre for Green Chemistry and Catalysis, Department of Chemistry, McGill University, 801 Sherbrooke St. West, Montreal, QC, H3A 0B8, Canada

\section{Author Contributions}

The paper was written through contributions of all authors. All authors have given approval to the final version of the paper.

\section{ACKNOWLEDGMENT}

We thank the Natural Science and Engineering Research Council of Canada (NSERC), the Canada Foundation for Innovation (CFI), the Canada Research Chairs (CRC), the Fonds de Recherche sur la Nature et les Technologies (FQRNT), the Center for Green Chemistry and Catalysis (CGCC) and McGill University for their financial support. We also thank Robin Stein 
Alain Y. Li, Andreanne Segalla, Chao-Jun Li, and Audrey Moores. Mechanochemical MetalFree Transfer Hydrogenation of Carbonyls Using Polymethylhydrosiloxane as the Hydrogen Source. ACS Sustainable Chemistry \& Engineering 20175 (12), 11752-11760 DOI: 10.1021/acssuschemeng.7b03298

and Thomas Di Nardo from McGill University for their precious help in ${ }^{13}$ C-MAS NMR experiments, and Nadim Saadé for the MALDI-TOF measurement. Tomislav Friščić, Patrick Julien, Jean-Louis Do and Blaine Fiss are warmly thanked for the useful discussions concerning the ball-milling technique.

Table of contents artwork

A mechanochemical method for carbonyl reduction is reported, using an inexpensive waste from the silicon industry as a reductant.

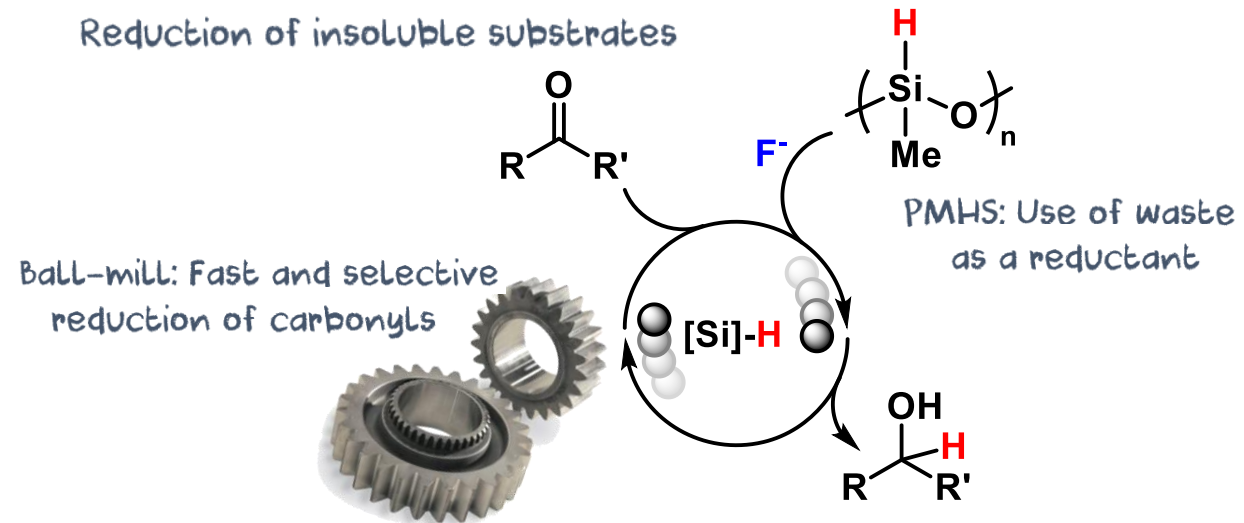

\section{REFERENCES}

1. Clarke, M. L.; Roff, G. J., Homogeneous Hydrogenation of Aldehydes, Ketones, Imines and Carboxylic Acid Derivatives: Chemoselectivity and Catalytic Activity. In The Handbook of Homogeneous Hydrogenation, Wiley-VCH Verlag GmbH: 2008; pp 413-454.

2. Brown, H. C.; Krishnamurthy, S., Forty years of hydride reductions. Tetrahedron 1979, 35 (5), 567-607.

3. Noyori, R., Pursuing practical elegance in chemical synthesis. Chem. Commun. 2005, (14), 1807-1811.

4. Wang, D.; Astruc, D., The Golden Age of Transfer Hydrogenation. Chem. Rev. 2015, 115 (13), 6621-6686.

5. Soni, R.; Hall, T. H.; Mitchell, B. P.; Owen, M. R.; Wills, M., Asymmetric Reduction of Electron-Rich Ketones with Tethered Ru(II)/TsDPEN Catalysts Using Formic Acid/Triethylamine or Aqueous Sodium Formate. J. Org. Chem. 2015, 80 (13), 6784-6793. 
Alain Y. Li, Andreanne Segalla, Chao-Jun Li, and Audrey Moores. Mechanochemical MetalFree Transfer Hydrogenation of Carbonyls Using Polymethylhydrosiloxane as the Hydrogen Source. ACS Sustainable Chemistry \& Engineering 20175 (12), 11752-11760 DOI: 10.1021/acssuschemeng.7b03298

6. Yang, J. W.; List, B., Catalytic Asymmetric Transfer Hydrogenation of $\alpha$-Ketoesters with Hantzsch Esters. Org. Lett. 2006, 8 (24), 5653-5655.

7. de Graauw, C. F.; Peters, J. A.; van Bekkum, H.; Huskens, J., Meerwein-Ponndorf-Verley Reductions and Oppenauer Oxidations: An Integrated Approach. Synthesis 1994, 1994 (10), 10071017.

8. Rendler, S.; Oestreich, M., Diverse Modes of Silane Activation for the Hydrosilylation of Carbonyl Compounds. In Modern Reduction Methods, Wiley-VCH Verlag GmbH \& Co. KGaA: 2008; pp 183-207.

9. Dobereiner, G. E.; Crabtree, R. H., Dehydrogenation as a substrate-activating strategy in homogeneous transition-metal catalysis. Chem. Rev. 2009, 110 (2), 681-703.

10. J. Lawrence, N.; D. Drew, M.; M. Bushell, S., Polymethylhydrosiloxane: a versatile reducing agent for organic synthesis. J. Chem. Soc., Perkin Trans. 1, 1999, (23), 3381-3391.

11. Verdaguer, X.; Berk, S. C.; Buchwald, S. L., Catalytic Method for the Reduction of Lactones to Lactols. J. Am. Chem. Soc. 1995, 117 (50), 12641-12642.

12. Lipshutz, B. H.; Noson, K.; Chrisman, W., Ligand-Accelerated, Copper-Catalyzed Asymmetric Hydrosilylations of Aryl Ketones. J. Am. Chem. Soc. 2001, 123 (51), 12917-12918.

13. Dal Zotto, C.; Virieux, D.; Campagne, J.-M., FeCl3-Catalyzed Reduction of Ketones and Aldehydes to Alkane Compounds. Synlett 2009, 2009 (02), 276-278.

14. Bette, V.; Mortreux, A.; Savoia, D.; Carpentier, J.-F., New developments in zinc-catalyzed asymmetric hydrosilylation of ketones with PMHS. Tetrahedron 2004, 60 (12), 2837-2842.

15. Patel, J. P.; Li, A.-H.; Dong, H.; Korlipara, V. L.; Mulvihill, M. J., Polymethylhydrosiloxane (PMHS)/trifluoroacetic acid (TFA): a novel system for reductive amination reactions. Tetrahedron Lett. 2009, 50 (44), 5975-5977.

16. Drew, M. D.; Lawrence, N. J.; Fontaine, D.; Sehkri, L.; Bowles, S. A.; Watson, W., A Convenient Procedure for the Reduction of Esters, Carboxylic Acids, Ketones and Aldehydes using Tetrabutylammonium Fluoride (or Triton ${ }^{\circledR}$ B) and Polymethylhydrosiloxane. Synlett 1997, 1997 (08), 989-991.

17. Kobayashi, Y.; Takahisa, E.; Nakano, M.; Watatani, K., Reduction of carbonyl compounds by using polymethylhydro-siloxane: reactivity and selectivity. Tetrahedron 1997, 53 (5), 1627 1634.

18. Revunova, K.; Nikonov, G. I., Base-Catalyzed Hydrosilylation of Ketones and Esters and Insight into the Mechanism. Chem. Eur. J. 2014, 20 (3), 839-845.

19. Mimoun, H.; de Saint Laumer, J. Y.; Giannini, L.; Scopelliti, R.; Floriani, C., Enantioselective Reduction of Ketones by Polymethylhydrosiloxane in the Presence of Chiral Zinc Catalysts. J. Am. Chem. Soc. 1999, 121 (26), 6158-6166.

20. Jacquet, O.; Das Neves Gomes, C.; Ephritikhine, M.; Cantat, T., Recycling of Carbon and Silicon Wastes: Room Temperature Formylation of $\mathrm{N}-\mathrm{H}$ Bonds Using Carbon Dioxide and Polymethylhydrosiloxane. J. Am. Chem. Soc. 2012, 134 (6), 2934-2937.

21. Jacquet, O.; Das Neves Gomes, C.; Ephritikhine, M.; Cantat, T., Complete Catalytic Deoxygenation of CO2 into Formamidine Derivatives. ChemCatChem 2013, 5 (1), 117-120.

22. von Wolff, N.; Lefèvre, G.; Berthet, J. C.; Thuéry, P.; Cantat, T., Implications of CO2 Activation by Frustrated Lewis Pairs in the Catalytic Hydroboration of CO2: A View Using N/Si+ Frustrated Lewis Pairs. ACS Catalysis 2016, 6 (7), 4526-4535.

23. Zhou, S.; Junge, K.; Addis, D.; Das, S.; Beller, M., A Convenient and General IronCatalyzed Reduction of Amides to Amines. Angew. Chem. 2009, 121 (50), 9671-9674. 
Alain Y. Li, Andreanne Segalla, Chao-Jun Li, and Audrey Moores. Mechanochemical MetalFree Transfer Hydrogenation of Carbonyls Using Polymethylhydrosiloxane as the Hydrogen Source. ACS Sustainable Chemistry \& Engineering 20175 (12), 11752-11760 DOI: 10.1021/acssuschemeng.7b03298

24. Rathke, J. W.; Klingler, R. J.; Krause, T. R., Propylene hydroformylation in supercritical carbon dioxide. Organometallics 1991, 10 (5), 1350-1355.

25. Samec, J. S. M.; Backvall, J.-E.; Andersson, P. G.; Brandt, P., Mechanistic aspects of transition metal-catalyzed hydrogen transfer reactions. Chem. Soc. Rev. 2006, 35 (3), 237-248.

26. Sheldon, R. A., Green solvents for sustainable organic synthesis: state of the art. Green Chem. 2005, 7 (5), 267-278.

27. James, S. L.; Adams, C. J.; Bolm, C.; Braga, D.; Collier, P.; Friscic, T.; Grepioni, F.; Harris, K. D. M.; Hyett, G.; Jones, W.; Krebs, A.; Mack, J.; Maini, L.; Orpen, A. G.; Parkin, I. P.; Shearouse, W. C.; Steed, J. W.; Waddell, D. C., Mechanochemistry: opportunities for new and cleaner synthesis. Chem. Soc. Rev. 2012, 41 (1), 413-447.

28. Chen, X.; Yang, H.; Zhong, Z.; Yan, N., Base-catalysed, one-step mechanochemical conversion of chitin and shrimp shells into low molecular weight chitosan. Green Chem. 2017, 19 (12), 2783-2792.

29. Toda, F.; Kiyoshige, K.; Yagi, M., NaBH4 Reduction of Ketones in the Solid State. Angew. Chem. Int. Ed. 1989, 28 (3), 320-321.

30. Mack, J.; Fulmer, D.; Stofel, S.; Santos, N., The first solvent-free method for the reduction of esters. Green Chem. 2007, 9 (10), 1041-1043.

31. Naimi-Jamal, M. R.; Mokhtari, J.; Dekamin, M. G.; Kaupp, G., Sodium Tetraalkoxyborates: Intermediates for the Quantitative Reduction of Aldehydes and Ketones to Alcohols through Ball Milling with NaBH4. Eur. J. Org. Chem. 2009, 2009 (21), 3567-3572.

32. Zhang, Z.; Gao, J.; Xia, J.-J.; Wang, G.-W., Solvent-free mechanochemical and one-pot reductive benzylizations of malononitrile and 4-methylaniline using Hantzsch 1,4-dihydropyridine as the reductant. Org. Biomol. Chem. 2005, 3 (9), 1617-1619.

33. Cravotto, G.; Gaudino, E. C., CHAPTER 3 Oxidation and Reduction by Solid Oxidants and Reducing Agents using Ball-Milling. In Ball Milling Towards Green Synthesis: Applications, Projects, Challenges, The Royal Society of Chemistry: 2015; pp 58-80.

34. Hua, D.; Hanxi, Y.; Xinping, A.; Chuansin, C., Hydrogen production from catalytic hydrolysis of sodium borohydride solution using nickel boride catalyst. Int. J. Hydrogen Energy 2003, 28 (10), 1095-1100.

35. Zheng, C.; You, S.-L., Transfer hydrogenation with Hantzsch esters and related organic hydride donors. Chem. Soc. Rev. 2012, 41 (6), 2498-2518.

36. Rak, M. J.; Saade, N. K.; Friscic, T.; Moores, A., Mechanosynthesis of ultra-small monodisperse amine-stabilized gold nanoparticles with controllable size. Green Chem. 2014, 16 (1), 86-89.

37. Friscic, T., Supramolecular concepts and new techniques in mechanochemistry: cocrystals, cages, rotaxanes, open metal-organic frameworks. Chem. Soc. Rev. 2012, 41 (9), 3493-3510.

38. Friščić, T.; Reid, D. G.; Halasz, I.; Stein, R. S.; Dinnebier, R. E.; Duer, M. J., Ion- and Liquid-Assisted Grinding: Improved Mechanochemical Synthesis of Metal-Organic Frameworks Reveals Salt Inclusion and Anion Templating. Angew. Chem. Int. Ed. 2010, 49 (4), 712-715.

39. Friscic, T.; Childs, S. L.; Rizvi, S. A. A.; Jones, W., The role of solvent in mechanochemical and sonochemical cocrystal formation: a solubility-based approach for predicting cocrystallisation outcome. CrystEngComm 2009, 11 (3), 418-426.

40. Howard, J. L.; Sagatov, Y.; Repusseau, L.; Schotten, C.; Browne, D. L., Controlling reactivity through liquid assisted grinding: the curious case of mechanochemical fluorination. Green Chem. 2017, 19 (12), 2798-2802. 
Alain Y. Li, Andreanne Segalla, Chao-Jun Li, and Audrey Moores. Mechanochemical MetalFree Transfer Hydrogenation of Carbonyls Using Polymethylhydrosiloxane as the Hydrogen Source. ACS Sustainable Chemistry \& Engineering 20175 (12), 11752-11760 DOI: 10.1021/acssuschemeng.7b03298

41. Do, J.-L.; Mottillo, C.; Tan, D.; Štrukil, V.; Friščić, T., Mechanochemical RutheniumCatalyzed Olefin Metathesis. J. Am. Chem. Soc. 2015, 137 (7), 2476-2479.

42. Grey, R. A.; Pez, G. P.; Wallo, A., Anionic metal hydride catalysts. 2. Application to the hydrogenation of ketones, aldehydes, carboxylic acid esters, and nitriles. J. Am. Chem. Soc. 1981, 103 (25), 7536-7542.

43. Goldberg, Y.; Ābele, E.; Shymanska, M.; Lukevics, E., Hydrosilylation of carbonyl compounds catalysed by alkali metal fluorides in the presence of crown ethers. J. Organomet. Chem. 1991, 410 (2), 127-133.

44. van Putten, R.-J.; van der Waal, J. C.; de Jong, E.; Rasrendra, C. B.; Heeres, H. J.; de Vries, J. G., Hydroxymethylfurfural, A Versatile Platform Chemical Made from Renewable Resources. Chem. Rev. 2013, 113 (3), 1499-1597.

45. Cukalovic, A.; Stevens, C. V., Production of biobased HMF derivatives by reductive amination. Green Chem. 2010, 12 (7), 1201-1206.

46. Liu, F.; Sivoththaman, S.; Tan, Z., Solvent extraction of 5-HMF from simulated hydrothermal conversion product. Sustain. Environ. Res. 2014, 24 (2), 149-157.

47. Saha, B.; Abu-Omar, M. M., Advances in 5-hydroxymethylfurfural production from biomass in biphasic solvents. Green Chem. 2014, 16 (1), 24-38.

48. Hu, L.; Lin, L.; Wu, Z.; Zhou, S.; Liu, S., Recent advances in catalytic transformation of biomass-derived 5-hydroxymethylfurfural into the innovative fuels and chemicals. Renewable and Sustainable Energy Reviews 2017, 74 (Supplement C), 230-257.

49. Drent, E.; Budzelaar, P. H. M., Palladium-Catalyzed Alternating Copolymerization of Alkenes and Carbon Monoxide. Chem. Rev. 1996, 96 (2), 663-682.

50. Milani, B.; Crotti, C.; Farnetti, E., Hydrogen transfer reduction of polyketones catalyzed by iridium complexes: a novel route towards more biocompatible materials. Dalton Trans. 2008, (34), 4659-4663.

51. Wu, H.; Zhao, W.; Hu, H.; Chen, G., One-step in situball milling synthesis of polymerfunctionalized graphene nanocomposites. J. Mater. Chem. 2011, 21 (24), 8626-8632.

52. Guo, J.; Wang, B.; Zhu, C., Copolymerization of carbon monoxide and styrene catalyzed by resin-supported palladium polymer. Express Polym. Lett. 2007, 1 (2), 69-76.

53. Baitinger, W. F.; Schleyer, P. v. R.; Murty, T. S. S. R.; Robinson, L., Nitro groups as proton acceptors in hydrogen bonding. Tetrahedron 1964, 20 (7), 1635-1647.

54. Goto, M.; Sato, M.; Hirose, T., Extraction of Peppermint Oil by Supercritical Carbon Dioxide. JOURNAL OF CHEMICAL ENGINEERING OF JAPAN 1993, 26 (4), 401-407.

55. Nguyen, K.; Barton, P.; Spencer, J. S., Supercritical carbon dioxide extraction of vanilla. The Journal of Supercritical Fluids 1991, 4 (1), 40-46.

ABSTRACT GRAPHIC 
Alain Y. Li, Andreanne Segalla, Chao-Jun Li, and Audrey Moores. Mechanochemical MetalFree Transfer Hydrogenation of Carbonyls Using Polymethylhydrosiloxane as the Hydrogen Source. ACS Sustainable Chemistry \& Engineering 20175 (12), 11752-11760 DOI: 10.1021/acssuschemeng.7b03298

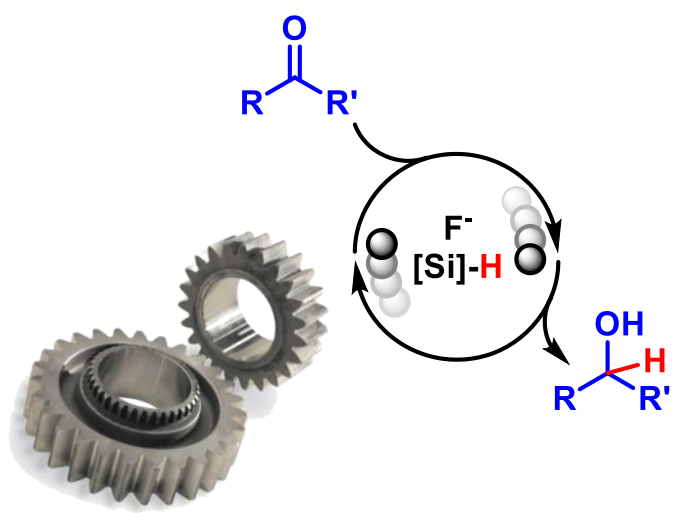

